\title{
Correction to: Novel CD44 receptor targeting multifunctional "nano-eggs" based on double pH-sensitive nanoparticles for co-delivery of curcumin and paclitaxel to cancer cells and cancer stem cells
}

\author{
Daquan Chen • Guohua Wang • Weiguo Song • Qiang Zhang
}

Published online: 18 February 2021

(C) Springer Nature B.V. 2021

Correction to: J Nanopart Res (2015) 17: 421

https://doi.org/10.1007/s11051-015-3217-9

The original version of this article unfortunately contained an error in the authors' preparation process. Figure 8 has been incorrectly reproduced. We have revised the error in the paper:

Novel CD44 receptor targeting multifunctional "nano-eggs" based on double $\mathrm{pH}$-sensitive

The online version of the original article can be found at https://doi.org/10.1007/s11051-015-3217-9

D. Chen $\cdot$ Q. Zhang $(\bowtie)$

School of Pharmaceutical Sciences, Health Science Center, Peking University, Beijing 100191, China

e-mail: zqdodo@bjmu.edu.cn

D. Chen $(\bowtie)$

School of Pharmacy, Yantai University, Yantai 264005, China e-mail: cdq1981@126.com

G. Wang

Institute of Chinese Materia Madica, China Academy of Chinese Medical Sciences, Beijing 100700, China

W. Song

Shouguang Fukang Pharmceutial Co., Ltd., Shouguang 262700, China nanoparticles for co-delivery of curcumin and paclitaxel to cancer cells and cancer stem cells

The corrected Fig. 8 is shown below:

Publisher's note Springer Nature remains neutral with regard to jurisdictional claims in published maps and institutional affiliations. 
Fig. 8 Fluorescence imaging of the cellular uptake of Cur-PTX$\mathrm{NE}$ (nano-eggs) at different times after incubation with MDA-MB231 cells: (a) Cur-PTX-NE (nano-eggs) (pH7.4) and (b) CurPTX-NE (nano-eggs) (pH 6.5)

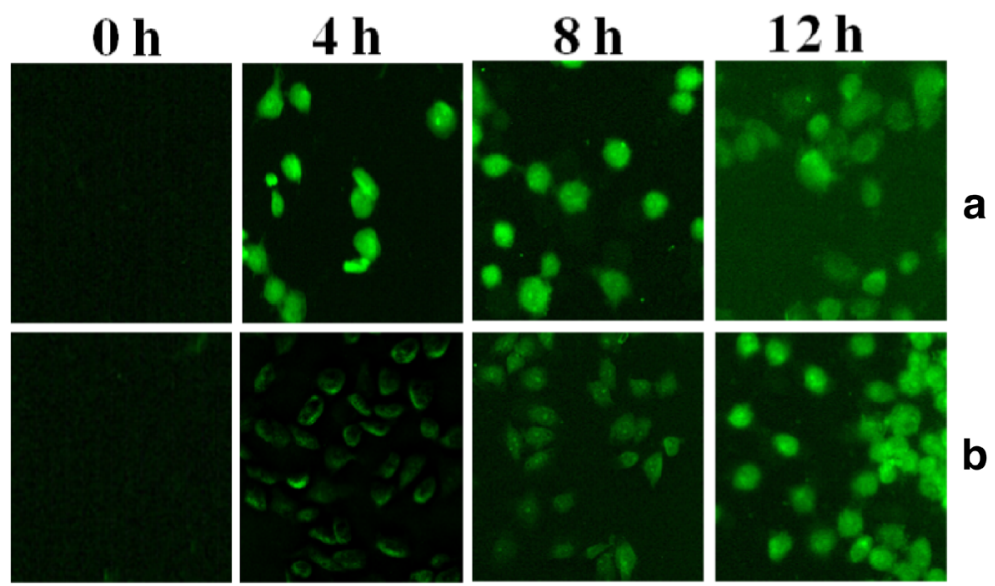

